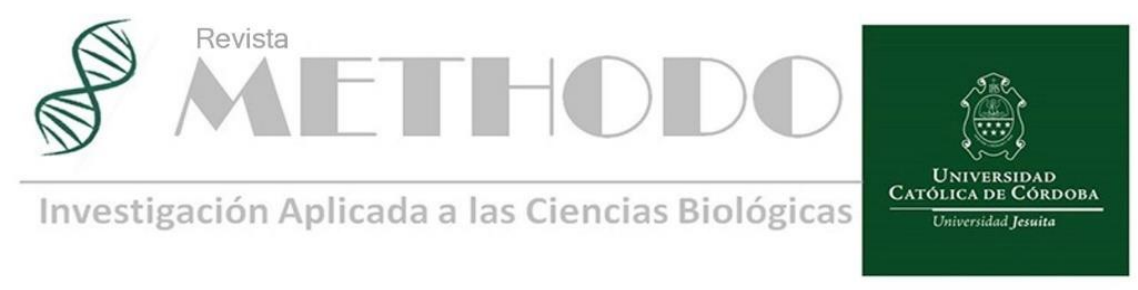

SEMBLANZA Rev. Methodo 2022;7(1):45-46

https://doi.org/10.22529/me.2022.7(1)08

Recibido 23 Sep. 2021 | Publicado 05 Ene. 2022

\title{
Dr. Alfredo Rodríguez (1918-2011)
}

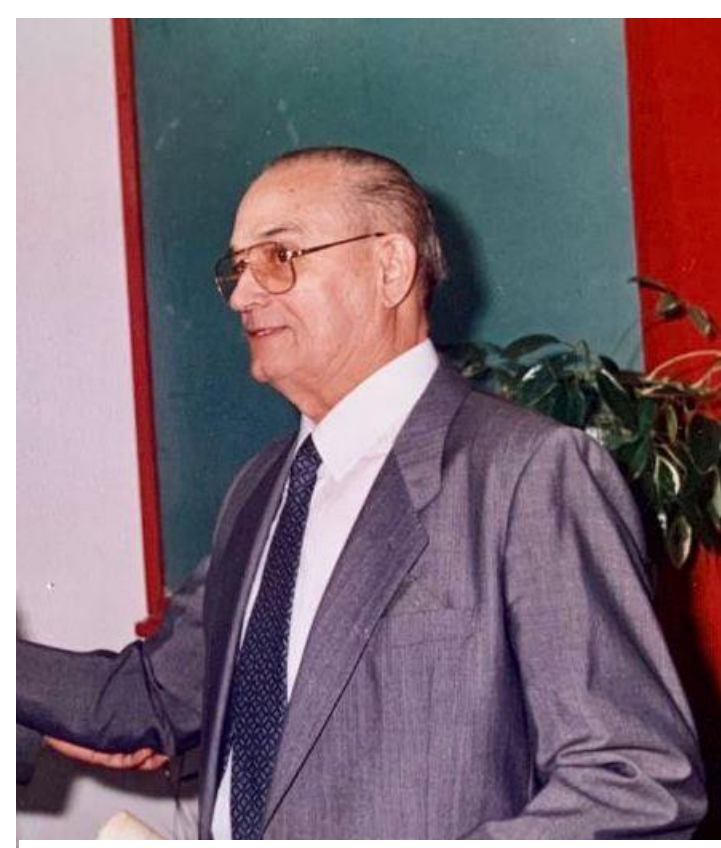

Figura 1. Dr. Alfredo Rodríguez

\section{Homenaje al Dr. Alfredo Rodríguez}

Cuando recibí la noticia de parte de las Autoridades de la Facultad de Medicina de la Universidad Católica de Córdoba (UCC) de escribir una semblanza de mi padre el Dr. Alfredo Rodríguez tuve la doble sensación, por un lado, la grata alegría por este reconocimiento y a la vez una gran responsabilidad por destacar lo que nosotros, sus dos hijos y sus 11 nietos reconocieron en el durante su vida familiar, médica y académica.

Papa nació un 5 de abril del año 1918 en la ciudad de Córdoba en la calle Santa Rosa, muy cerca del
Hospital de Clínicas y del club de sus amores Belgrano.

La vida de papa transcurrió invariablemente entre su vida familiar y la médica. Familia a la que le transmitió todos los valores que él consideraba como esenciales a la vida de un católico practicante yo diría hasta militante de su fe cristiana, aunque sin embargo con una mirada abierta y comprensiva hacia los cambios que continuamente fueron sucediendo en el mundo y en nuestra Argentina. Estudioso, de sereno juicio, tolerante y firme en sus convicciones. Disfrutaba de la lectura, los idiomas y la música clásica.

Su vida profesional se inició el Instituto de Cardiología de la Av. General Paz, posteriormente en la Clinica Universitaria Reina Fabiola de la Univeraidad Católica de Córdoba, el Hospital Agesilao Milano de la Fuerza Aérea Argentina donde se desempeñó desde su inauguración como Jefe de Cardiología y además atendiendo en su consultorio particular a sus numerosos pacientes hasta altas horas de la noche. A partir del año 1956 cuando se crea la Universidad Católica de Córdoba y la Facultad de Medicina es nombrado Profesor Titular de la Catedra de Medicina Legal del Trabajo y Deontología Médica siendo a su vez miembro fundador de esta última. A pesar de esta apretada agenda profesional y académica, siempre estuvo presente en todos los acontecimientos más importantes de nuestra vida familiar y de su querida compañera de toda su vida nuestra madre Beba.

En las aulas de la UCC es donde transcurrieron los mejores años de su vida académica y donde además cultiva estrecha amistad con muchos de sus miembros y autoridades, algunas de ellas ya habían sido sus amigos de la adolescencia.

Revista Methodo: Investigación Aplicada a las Ciencias Biológicas. Universidad Católica de Córdoba. Jacinto Ríos 571 Bo Gral. Paz. X5004FXS. Córdoba. Argentina. Tel.: (54) 3514517299 / Correo: methodo@ucc.edu.ar / Web: methodo.ucc.edu.ar | SEMBLANZA Rev. Methodo 2022;7(1):45-46. 
Recuerdo en mi vida de estudiante y ya siendo médico en mis primeros años, las tertulias frecuentes y prolongadas en su casa durante la larga trayectoria como decano de la Facultad de Ciencias Médicas (1973-1984) con los RP Cesar Azua, Fernando Storni, Hipólito Salvo, Jean Sonet, Alberto Fourcade entre otros.

Desde su ingreso como Profesor en 1956 siguiendo por su designación como decano en 1973 hasta ya entrado en este nuevo milenio su vida no pudo separarse de sus actividades académicas en la UCC ni de su entrañable amistad con el RP Cesar Azua. En el año 1978 acompaña al R. P. Jean Joseph Sonet, en un extenso y muy fructífero viaje a Europa y Bélgica que se traduce en el apoyo de los Reyes de Bélgica al Hospital /Escuela Clínica Reina Fabiola.

Durante su largo decanato también entrego el título de Dr. Honoris Causa en el año 1974 al Dr. Rene G Favaloro, que fue la primera distinción académica del prestigioso cardiocirujano de una Universidad Argentina.

De esta Facultad de Medicina y de la UCC, papá además recibió los títulos de Profesor Emérito en el año 1995 y de Maestro de la Medicina en el 2011. Su espíritu científico e inquieto lo llevo a terminar su Tesis de Doctorado en el año 1979, UCC, sobre el tema de Corazón Senil, trabajo que había comenzado en el año 1954 y que por diversas circunstancias lo había postergado.

En esa Tesis, donde se muestran varios cortes anatomopatológicos que como están descriptos en la Figura1, el ya entonces mostraba la relevancia de la grasa perivascular y miocárdica refiriéndose a "gránulos de grasa miocárdicos por sufrimiento anoxico" sugiriendo una relación con la isquemia y el daño funcional. Esto que casi 20 años después se define y describe como metaplasia lipomatosa, está hoy siendo profundamente estudiada por los nuevos métodos no invasivos como la tomografía multicorte y la resonancia nuclear cardíaca, papá ya entonces sugería su importancia, en los cortes anatomopatológicos reproducidos en esta Figura1 de su Tesis (Paneles A y B).

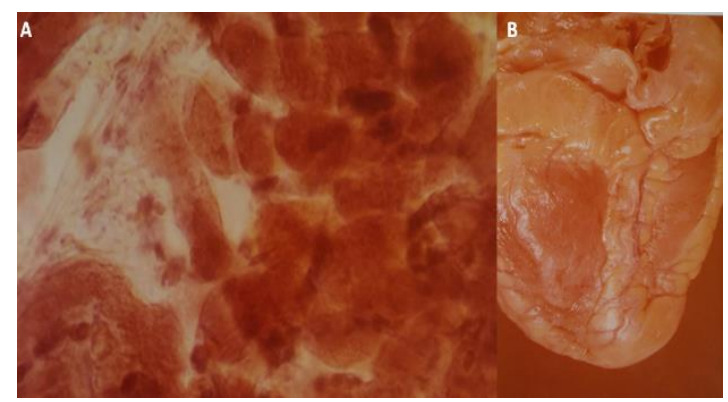

Figura 1. (Paneles A y B).
Es imposible poder sintetizar en pocas líneas lo que mi padre significó para mí. Él supo conjugar con sutil equilibrio la vida familiar con la academia y el ámbito científico. Me parece adecuado para finalizar traer las palabras del Profesor de Cirugía de la UCC y reconocido especialista, Dr. Octavio Gil, que, como amigo de mi infancia, tuvo la oportunidad de conocerlo en la intimidad:

"Recordar al Dr. Alfredo Rodríguez nos retrotrae con profunda nostalgia, no sólo, a aquella época dorada de estudiantes, a los momentos compartidos, al título de Médico, Diploma que tuve el privilegio de recibir de sus manos; sino también entraña un profundo sentimiento de respeto y admiración por una personalidad afable y sensible con una dedicación permanente a su profesión como Clínico y Cardiólogo y fundamentalmente a su familia que representaba el centro de sus desvelos. Su semblanza fue el estudio continuo y permanente que mantuvo como guía de su vida Médica y Docente

Si debiéramos definir al Dr. Rodríguez con sólo una palabra, diríamos que fue una persona INTEGRA, ejemplo a seguir por nosotros y futuras generaciones para lograr enaltecer nuestra profesión y nuestra Argentina."

Continúan su legado 4 nietos médicos cardiólogos.

Papá falleció el 12 de noviembre del año 2011.

Alfredo E Rodríguez MD, PhD, FACC, FSCAI

(Jefe Cardiología Intervencionista Sanatorio Otamendi Buenos Aires, Argentina).

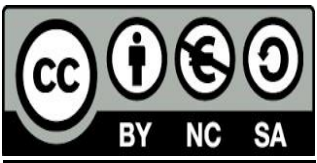

Revista Methodo: Investigación Aplicada a las Ciencias Biológicas. Universidad Católica de Córdoba. Jacinto Ríos 571 Bo Gral. Paz. X5004FXS. Córdoba. Argentina. Tel.: (54) 3514517299 / Correo: methodo@ucc.edu.ar / Web: methodo.ucc.edu.ar | SEMBLANZA Rev. Methodo 2022;7(1):45-46. 